Article

\title{
Effect of Sputtering Temperature on Fluorocarbon Films: Surface Nanostructure and Fluorine/Carbon Ratio
}

\author{
Qi Zhao ${ }^{1} \mathbb{D}$, Feipeng Wang ${ }^{1, *}{ }^{\mathbb{D}}$, Kaizheng Wang ${ }^{1}$, Guibai Xie ${ }^{2}$, Wanzhao Cui ${ }^{2} \mathbb{D}$ and Jian Li ${ }^{1}$ \\ 1 State Key Laboratory of Power Transmission Equipment \& System Security and New Technology, \\ Chongqing University, Chongqing 400044, China; zhaoqi@cqu.edu.cn (Q.Z.); \\ 20131002018@cqu.edu.cn (K.W.); lijian@cqu.edu.cn (J.L.) \\ 2 National Key Laboratory of Science and Technology on Space Microwave, China Academy of Space \\ Technology (Xi'an), Xi'an 710100, China; xieguibai@163.com (G.X.); cuiwanzhao@126.com (W.C.) \\ * Correspondence: fpwang@cqu.edu.cn; Tel.: +86-185-8076-8887
}

Received: 4 May 2019; Accepted: 24 May 2019; Published: 3 June 2019

\begin{abstract}
In this work, fluorocarbon film was deposited on silicon (P/100) substrate using polytetrafluoroethylene (PTFE) as target material at elevated sputtering temperature. Field emission scanning electron microscopy (FESEM), atomic force microscopy (AFM), Raman spectroscopy and $\mathrm{X}$-ray photoelectron spectroscopy (XPS) were employed to investigate the surface morphology as well as structural and chemical compositions of the deposited film. The surface energy, as well as the polar and dispersion components, were determined by water contact angle (WCA) measurement. The experimental results indicated that increasing sputtering temperature effectively led to higher deposition rate, surface roughness and WCA of the film. It was found that the elevated temperature contributed to increasing saturated components (e.g., $C-\mathrm{F}_{2}$ and $\mathrm{C}-\mathrm{F}_{3}$ ) and decreasing unsaturated components (e.g., $\mathrm{C}-\mathrm{C}$ and $\mathrm{C}-\mathrm{CF}$ ), thus enhancing the fluorine-to-carbon $(\mathrm{F} / \mathrm{C})$ ratio. The results are expected aid in tailoring the design of fluorocarbon films for physicochemical properties.
\end{abstract}

Keywords: fluorocarbon; surface nanostructure; sputtering temperature; surface properties

\section{Introduction}

Fluorocarbon film, due to its superior hydrophobicity, low dielectric constant and small friction coefficient, is a promising material in various fields (e.g., self-cleaning coatings for perovskite solar cells, interlayer dielectrics in integrated circuits and lubricant coatings in micro-machines) [1-3]. Based on these attractive properties, a variety of approaches have been applied to fabricate fluorocarbon films, such as dielectric barrier discharge (DBD), ion beam sputter depositing (IBSD) and plasma-enhanced chemical vapor deposition (PECVD) [4-6]. However, drawbacks like induced impurities, small-scale deposition, as well as harmful and expensive raw materials (e.g., $\mathrm{CF}_{4}, \mathrm{C}_{4} \mathrm{~F}_{8}$ and $\mathrm{C}_{5} \mathrm{~F}_{8}$ ) restrict their extensive applications. Radio-frequency (RF) sputtering is quoted as an excellent alternative for fluorocarbon film fabrication owing to its capability of large-scale deposition, safe preparation process and excellent process controllability [7-9]. The sputtered fluorocarbon film exhibits improved physicochemical properties (e.g., lubrication, chemical inertness and thermal stability) by controlling the fabrication process to form a structure similar to that of polytetrafluoroethylene (PTFE). The PTFE-like fluorocarbon film with improved physicochemical properties is expected and pursued in various fields $[10,11]$.

The deposition of fluorocarbon films is controlled by various factors, including sputtering type $[12-14]$, target material $[15,16]$ and substrate temperature $[17,18]$-all of which govern the modulus, hardness and wettability by adjusting the elemental composition and surface morphology. 
Since the deposition is a plasma-associated process, much is known of the sputtering power [19], target-substrate distance [20,21] and gas conditions [22-25] that vary the plasma conditions, leading to various fluorocarbon film characteristics (e.g., electrical conductivity, scratch resistance and thermal stability). Additionally, the chamber temperature has been documented to affect the surface topography and wettability of fluorocarbon films [26]. The phenomenon of an elevated chamber temperature leading to plasma color transformation from light red to dark red is also observed in our experiments. As is well-known, the color change manifests variations of plasma species, density and temperature, etc. [27]. This prompted us to investigate the influence of sputtering temperature, which includes the chamber and substrate temperatures, on fluorocarbon film deposition. This work aimed to obtain full-scale understanding of the kinetic energies of argon ions, the collisions between argon atoms and ejected fragments (e.g., C-C, C-CF, C-F), as well as the adsorption capabilities of ejected fragments by discovering the variations of surface topography and elemental composition with sputtering temperature.

\section{Materials and Methods}

Figure 1 shows the RF (13.56 MHz) magnetron sputtering system for fluorocarbon film fabrication. The vacuum chamber of the sputtering system was in a "sputter-up" configuration with a PTFE target (purity 99.99\%, diameter 3 inches, thickness $4 \mathrm{~mm}$ ). The silicon substrate (size $4 \times 4 \mathrm{~mm}^{2}$, thickness 0.5 $\mathrm{mm}$ ) was mounted on top of the chamber with the capability of adjusting temperature $\left(50-200{ }^{\circ} \mathrm{C}\right)$ by an installed heater and a thermocouple. The stainless-steel heating elements were fixed around the substrate with another thermocouple monitoring the chamber temperature.

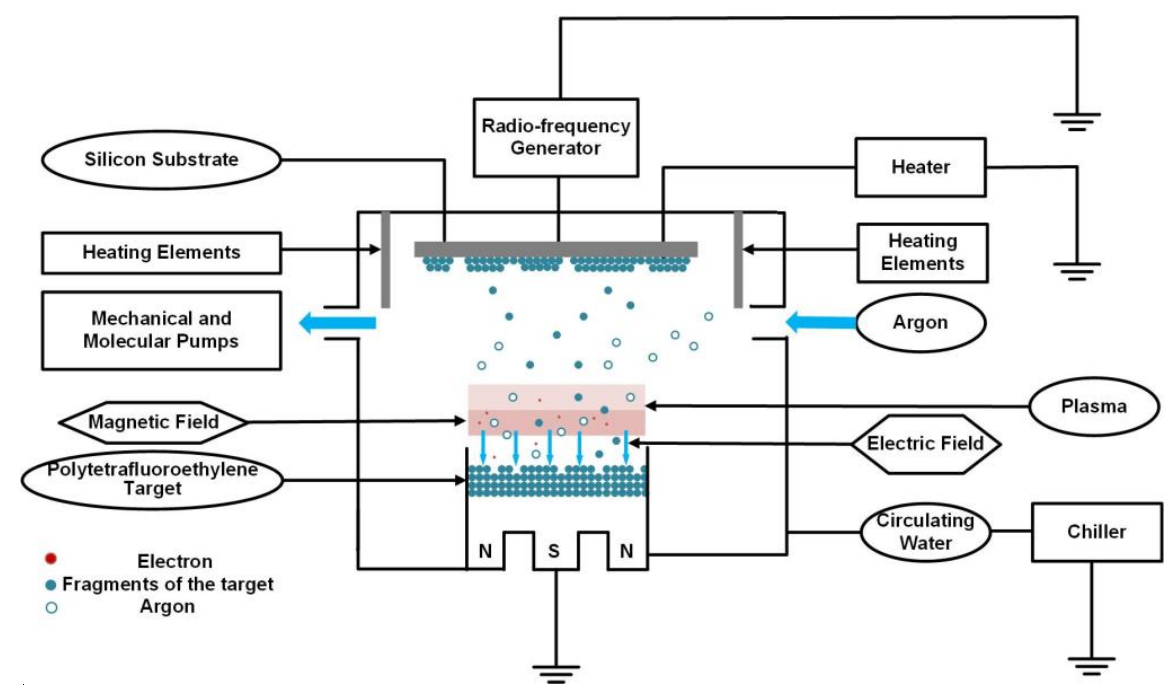

Figure 1. Schematic diagram of the magnetron sputtering system.

The silicon substrate was ultrasonically cleaned by anhydrous alcohol and deionized water successively, and then dried in nitrogen before being loaded into the chamber. The chamber was evacuated to a base pressure of $5 \times 10^{-4} \mathrm{~Pa}$. The PTFE target was pre-sputtered in argon plasma for 15 min in order to remove excessive oxide surface layer. The sputtering was conducted in argon plasma at a target-substrate distance of $100 \mathrm{~mm}$, a working pressure of $0.5 \mathrm{~Pa}$ and a discharge power of $80 \mathrm{~W}$ for $1 \mathrm{~h}$. Both the chamber and substrate temperatures were controlled at the same value. Each experiment was done at a fixed temperature of $50,100,150$ and $200^{\circ} \mathrm{C}$.

The film thickness was an average value of five measurements taken by a surface profiler (Dektak XT, Bruker, Germany). Field-emission scanning electron microscopy (FESEM, JSM-7800F, JEOL, Tokyo, Japan) with a beam accelerating voltage of $20 \mathrm{kV}$ was applied to inspect the surface morphology of fluorocarbon films. An atomic force microscope (AFM, MFP-3D-BIO, Asylum Research, Goleta, CA, USA) working in contact mode was utilized to measure the arithmetic average of the roughness profile 
$\left(R_{a}\right)$. The AFM provided quantitative information about surface structures through a mechanical tip which scans and senses the surface. The static water contact angle (WCA) was examined on a WCA goniometer (SDC-100, SINDIN, Chengdu, China). Both contact angles of water and methylene iodide with the droplet volume of $10 \mu \mathrm{L}$ were measured at room temperature. The polar component $\left(\gamma_{\mathrm{s}}^{\mathrm{p}}\right)$ and dispersion component $\left(\gamma_{\mathrm{s}}{ }^{\mathrm{d}}\right)$ of the surface free energy $\left(\gamma_{\mathrm{s}}{ }^{\mathrm{owk}}\right)$ were calculated by applying the contact angles of water and methylene iodide to the Owens-Wendt-Kaelble (OWK) approach and Young's equation (Equations (1) and (2)) [28].

$$
\begin{gathered}
\gamma_{s}{ }^{\text {owk }}=\gamma_{s}{ }^{p}+\gamma_{s}{ }^{d} \\
\gamma_{L} \cdot(1+\cos \theta)=2\left[\left(\gamma_{s}^{d} \gamma_{L}^{d}\right)^{1 / 2}+\left[\left(\gamma_{s}{ }^{p} \gamma_{L}{ }^{p}\right)^{1 / 2}\right]\right.
\end{gathered}
$$

In Equation (2), the parameters of $\theta$ and $\gamma_{L}$ indicate the measured contact angles and the known surface free energy of water and methylene iodide, respectively. The structural changes of fluorocarbon films were determined by Raman spectroscopy (LabRAM HR Evolution, HORIBA Jobin Yvon S.A.S, Palaiseau, France) with laser wavelength of $325 \mathrm{~nm}$. Based on the interaction of light with chemical bonds within the films, the non-destructive light scattering technique provides detailed spectra, which demonstrates the intensity and wavelength position of the Raman scattered light. The chemical composition was evaluated through X-ray photoelectron spectroscopy (XPS, ESCALAB 250Xi, Thermo Scientific, Waltham, MA, USA) with $\mathrm{Al} \mathrm{K} \alpha$ radiation $(1486.6 \mathrm{eV})$ at a power of $25 \mathrm{~W}$. Charging of the films that resulted from photoemission was calibrated using adventitious carbon referencing (C 1s, $284.6 \mathrm{eV}$ ). The spot size of the X-ray beam was $500 \times 500 \mu \mathrm{m}^{2}$ in each case.

\section{Results and Discussion}

Figure 2 exhibits the overall XPS spectra of fluorocarbon films with elevated temperature. The dominant peak of $\mathrm{F}$ 1s with small peaks of $\mathrm{C} 1 \mathrm{~s}, \mathrm{O}$ 1s and $\mathrm{O} 2 \mathrm{~s}$ in XPS spectra verify the successful deposition of the films on the substrate. Compared with the molecular formula of PTFE $\left(\left[\mathrm{C}_{2} \mathrm{~F}_{4}\right]_{\mathrm{n}}\right)$, the appearance of weak $\mathrm{O} 1 \mathrm{~s}$ and $\mathrm{O} 2 \mathrm{~s}$ peaks indicates that a small amount of oxygen was present in fluorocarbon films, which may be due to the residual contaminations on the substrate, as well as the oxidation of the films when exposed to the atmosphere. Furthermore, the peak intensities of $C 1 \mathrm{~s}$ and $\mathrm{F}$ 1 s increased while those of $\mathrm{O} 1 \mathrm{~s}$ and $\mathrm{O}$ 2s decreased with the elevated temperature. The phenomenon was probably caused by the removal of adsorbed contaminants from the substrate, which resulted from the increased substrate temperature. Accordingly, the elevated temperature was beneficial for improving the purity of the fluorocarbon films.

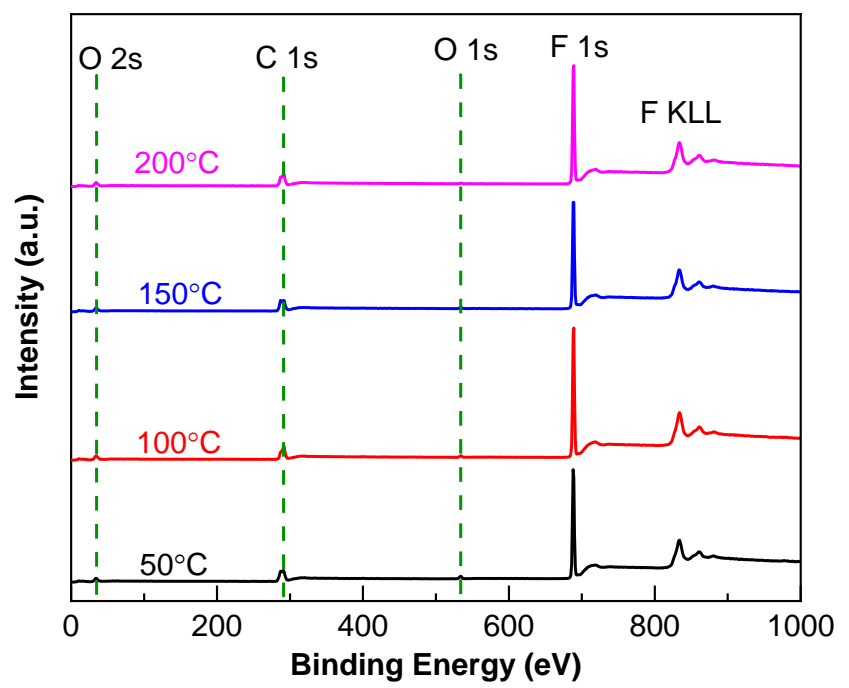

Figure 2. Full-scan XPS spectra of fluorocarbon films as a function of sputtering temperature. 
The XPS spectra related to the $\mathrm{C}$ 1s signal (Figure 3) were divided into five peaks at the binding energies of $284.2,286.8,289.7,291.5$ and $293.5 \mathrm{eV}$, suggesting the existence of $\mathrm{C}-\mathrm{C}, \mathrm{C}-\mathrm{CF}, \mathrm{C}-\mathrm{F}, \mathrm{C}-\mathrm{F}_{2}$ and $\mathrm{C}-\mathrm{F}_{3}$ bonds, respectively $[14,29-32]$. The expression of $\mathrm{C}-\mathrm{F}, \mathrm{C}-\mathrm{F}_{2}$ and $\mathrm{C}-\mathrm{F}_{3}$ means that the carbon atoms are linked to one, two and three fluorine atoms, respectively, while $\mathrm{C}-\mathrm{CF}$ indicates the connection of one carbon atom to another carbon atom, which is bound with a fluorine atom. In addition, $\mathrm{C}-\mathrm{C}$ demonstrates that only two carbon atoms are linked together. The area under each peak indicates the relative presence of each bond type.
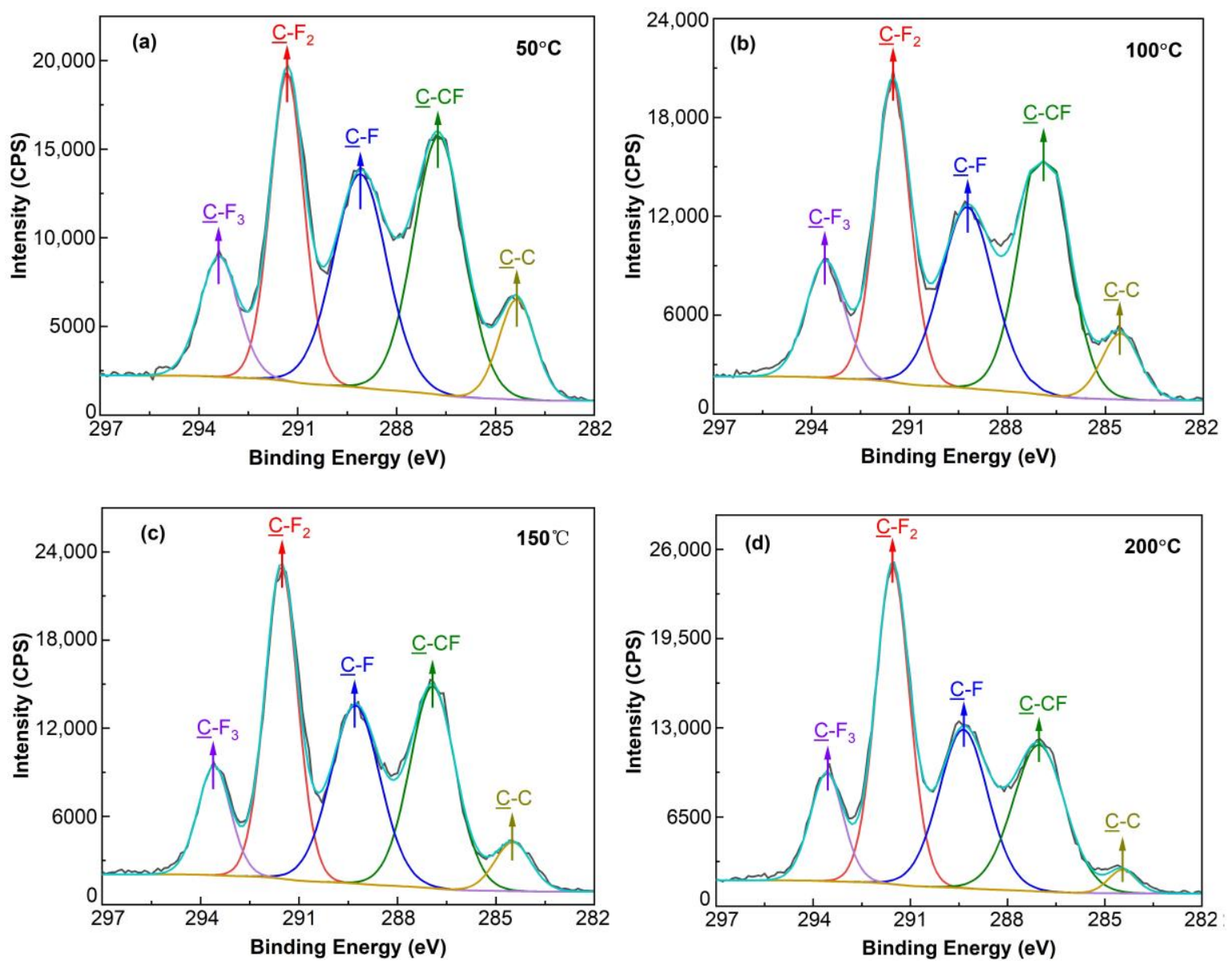

Figure 3. The $\mathrm{C} 1 \mathrm{~s}$ spectra of fluorocarbon films deposited at the sputtering temperature of $50{ }^{\circ} \mathrm{C}(\mathbf{a})$, $100{ }^{\circ} \mathrm{C}(\mathbf{b}), 150{ }^{\circ} \mathrm{C}(\mathbf{c})$ and $200{ }^{\circ} \mathrm{C}(\mathbf{d})$.

The elevated temperature was beneficial for the enhanced atomic concentrations of $C-\mathrm{F}_{2}$ and $\mathrm{C}-\mathrm{F}_{3}$, which increased to $37.15 \%$ and $11.64 \%$, respectively (Figure 4). Meanwhile, the atomic concentrations of $\mathrm{C}-\mathrm{C}$ and $\mathrm{C}-\mathrm{CF}$ dramatically reduced down to $1.13 \%$ and $27.12 \%$, respectively. However, the atomic concentration of $\mathrm{C}-\mathrm{F}$ fluctuated, first increasing from $22.52 \%$ to $23.77 \%$, and then decreasing from $23.77 \%$ to $22.96 \%$, via $23.02 \%$. The calculated $\mathrm{F} / \mathrm{C}$ ratio of fluorocarbon films exhibited an increasing trend, from 0.99 to 1.24 (via 1.05 and 1.11) with the elevation of temperature from 50 to $200{ }^{\circ} \mathrm{C}$, via 100 and $150{ }^{\circ} \mathrm{C}$. 


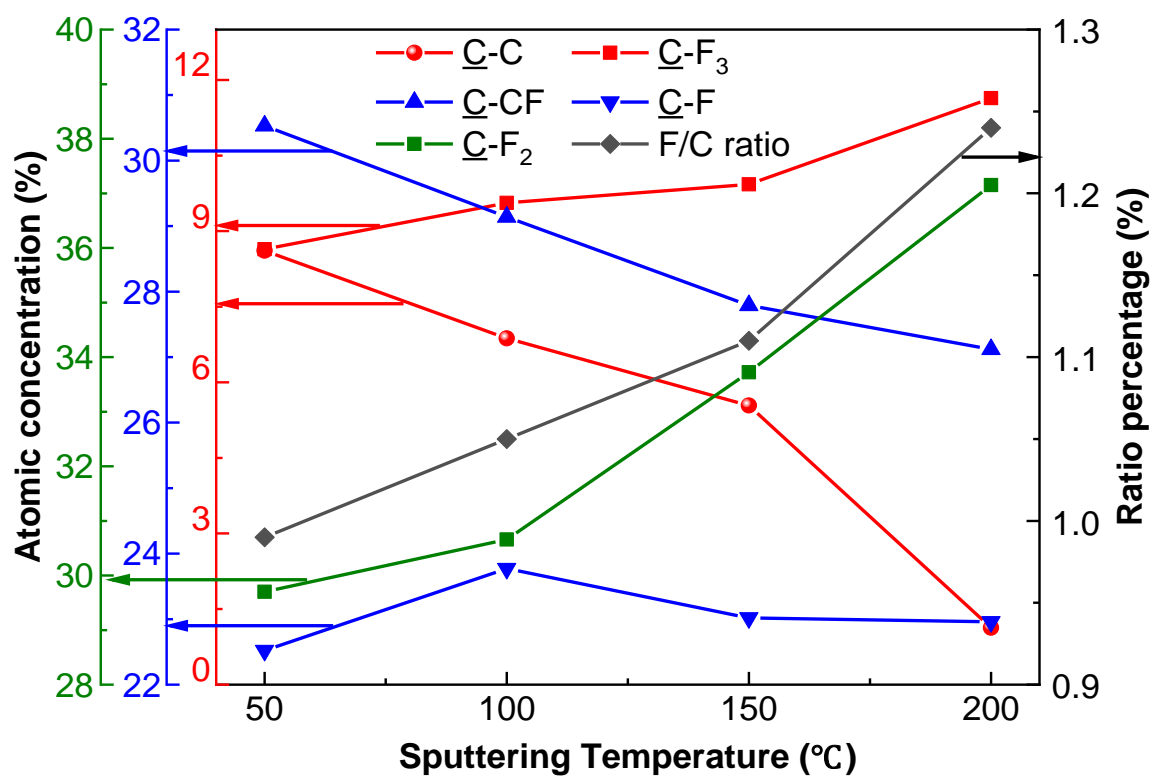

Figure 4. Atomic concentrations of chemical bonds and F/C ratio of fluorocarbon films.

For the PTFE target characterized by long chains of fluorinated carbons, $\left[\mathrm{CF}_{2}-\mathrm{CF}_{2}\right]_{n}$ served as the bulk of the chain. The appeared chemical bonds of $C-C, C-C F$ and $C-F_{x}(x=1,2,3)$ indicate that the chain had broken due to the collisions between the target and argon. As the bond dissociation energy of $C-C(618.3 \pm 15.4 \mathrm{~kJ} / \mathrm{mol})$ is higher than that of $\mathrm{C}-\mathrm{F}(513.8 \pm 10.0 \mathrm{~kJ} / \mathrm{mol})$, the formation of $\mathrm{C}-\mathrm{C}$ bonds is much easier than the formation of $\mathrm{C}-\mathrm{F}$ bonds [33]. The survival competition between the saturated components (SCs, e.g., $\mathrm{C}-\mathrm{F}_{3}, \mathrm{C}-\mathrm{F}_{2}$ ) and the unsaturated components (UCs, e.g., $\mathrm{C}-\mathrm{C}$, $\mathrm{C}-\mathrm{CF}$ ) on the substrate indicates that the formation of SCs requires a higher momentum transfer. Therefore, the proportion of SCs increased with the elevated substrate temperature. The survival competition between UCs and SCs was confirmed by the increased proportions of $\mathrm{C}-\mathrm{F}_{2}$ and $\mathrm{C}-\mathrm{F}_{3}$, as well as the relatively decreased proportions of $\mathrm{C}-\mathrm{C}$ and $\mathrm{C}-\mathrm{CF}$. As the structure of the PTFE target is long continuous chains with fluorinated carbon twisted into a helix, the fluorine sheath of PTFE exhibits a compact "capsule" structure. The fluorine sheath consists of C-F bonds. The initial breaking of $\mathrm{C}-\mathrm{F}$ bonds offers opportunities for argon ions to collide with $\mathrm{C}-\mathrm{C}$ bonds inside the sheath, resulting in the breaking of $\mathrm{C}-\mathrm{C}$ bonds. Therefore, although the elevated substrate temperature was beneficial for the formation of a higher proportion of $\mathrm{C}-\mathrm{F}$ bonds on the substrate, the atomic concentration of $\mathrm{C}-\mathrm{F}$ fluctuated with the sputtering temperature. The increased $\mathrm{F} / \mathrm{C}$ ratio was consequently caused by the formation of a higher proportion of SCs and a lower proportion of UCs on the substrate. Accordingly, the elevated sputtering temperature contributed to increasing the $\mathrm{F} / \mathrm{C}$ ratio, which favors the formation of PTFE-like fluorocarbon films with superior physicochemical properties [34,35].

Figure 5 shows a nonlinear relationship between sputtering temperature and the deposition rate of fluorocarbon films. The elevated temperature from 50 to $200^{\circ} \mathrm{C}$ effectively increased the deposition rate from 1.25 to $4.13 \mathrm{~nm} / \mathrm{min}$, via 2.91 and $3.43 \mathrm{~nm} / \mathrm{min}$. The sputtering temperature covered both the chamber and substrate temperatures. The elevated chamber temperature induced the increased temperature of argon ions. Higher temperature of argon ions prolongs its mean free path $\left(\lambda_{\mathrm{fp}}^{\prime}\right)$, according to Equations (3) and (4). In these equations, $\mathrm{N}$ relates to the density of argon ions. $\mathrm{P}_{\mathrm{g}}$ and $\mathrm{T}_{\mathrm{g}}$ refer to the pressure and temperature of argon ions. $\mathrm{K}_{\mathrm{B}}$ is the Boltzmann constant. $\sigma$ indicates the geometric cross section between argon ions and other particles (e.g., argon atoms and ejected fragments) during collisions. 


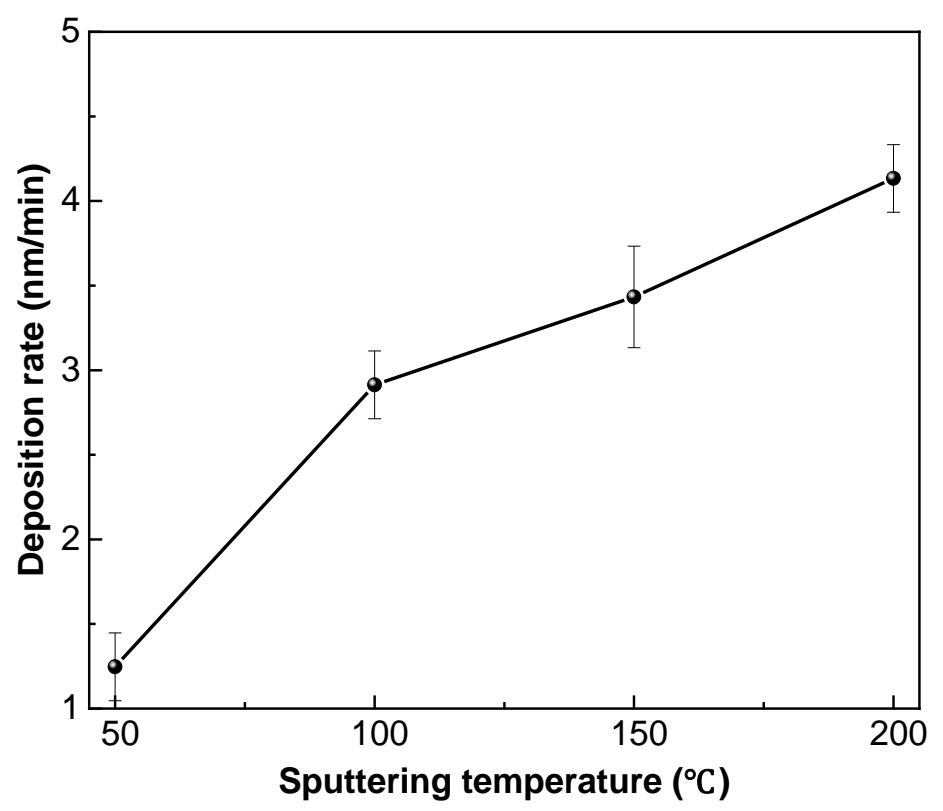

Figure 5. Deposition rate of fluorocarbon films as a function of sputtering temperature (error bars indicate $95 \%$ confidence intervals).

$$
\begin{gathered}
\mathrm{N}=\mathrm{P}_{\mathrm{g}} /\left(\mathrm{K}_{\mathrm{B}} \cdot \mathrm{T}_{\mathrm{g}}\right) \\
\lambda=1 /(\mathrm{N} \cdot \sigma) \\
\mathrm{E}_{\mathrm{i}}=2\left(\lambda_{\mathrm{fp}}^{\prime} / \mathrm{L}\right) \cdot\left(\mathrm{e} \cdot \mathrm{V}_{\mathrm{c}}\right)
\end{gathered}
$$

Based on Equation (5), the prolonged $\lambda_{\text {fp }}^{\prime}$ increases the average energy $\left(E_{i}^{\prime}\right)$ of argon ions. $L$ is the distance between the cathode and the anode of the RF sputtering system. $V_{c}$ indicates the cathode fall voltage and e refers to the electron charge [36]. The elevated chamber temperature should be beneficial for increasing the ion temperature, as well as the ion energy. However, the ion energy gained from the higher chamber temperature is less than $1 \%$ of that from the power supply. This phenomenon guides us to focus the process of the fragments from target to substrate, which could be strongly influenced by the elevated chamber temperature.

The higher chamber temperature increases the temperature of ejected fragments, resulting in their prolonged mean free path $\left(\lambda^{\prime \prime}{ }_{\mathrm{fp}}\right)$. The prolonged $\lambda_{\text {fp }}$ decreases the number of effective collisions between ejected fragments and other particles (e.g., argon ions and atoms), which is helpful to reduce the kinetic energy loss of ejected fragments. Furthermore, the prolonged $\lambda^{\prime \prime}{ }_{\mathrm{fp}}$ is beneficial for the increased average energy $\left(E^{\prime \prime}{ }_{i}\right)$ of ejected fragments, thus contributing to the successful deposition of ejected fragments on the substrate [37].

Elevated substrate temperature has been reported to have a negative effect on fluorocarbon film deposition, due to the negative apparent activation energy, which promotes desorption rather than adsorption of ejected fragments on the substrate [10]. The promoted desorption reduces the sticking coefficient of ejected fragments, thus weakening their adhering capabilities to the substrate [17]. The sticking coefficient depicts a probability for the ejected fragments to be trapped on the surface of the silicon substrate through losing their kinetic energy by transferring their energy to the silicon atoms. However, the reduced sticking coefficient tends to be offset by the increased $\mathrm{E}_{\mathrm{i}}$ [29]. In addition, the atomic concentrations of larger fragments (e.g., $\mathrm{C}-\mathrm{F}_{2}, \mathrm{C}-\mathrm{F}_{3}$ ) increases with the elevated sputtering temperature (Figure 4). As larger fragments exhibit a higher sticking coefficient than smaller fragments (e.g., $\mathrm{C}-\mathrm{C}$ and $\mathrm{C}-\mathrm{CF}$ ), the increased atomic concentrations of larger fragments help to increase the sticking coefficient of fluorocarbon films [29]. Moreover, the elevated substrate temperature is beneficial for fluorocarbon film densification by enhancing the re-condensation process of ejected fragments on 
the substrate [38]. Accordingly, the elevated sputtering temperature is beneficial for more efficient fluorocarbon film deposition, through the decreased energy loss, improved sticking coefficient and enhanced re-condensation of ejected fragments.

Figure 6 shows the nanostructural evolution of fluorocarbon films as a function of elevated sputtering temperature. It can be seen that the films consisted of almost spherical grains with an equivalent diameter of $100 \mathrm{~nm}$. For the temperatures of 50 and $100{ }^{\circ} \mathrm{C}$, the amount of grains was relatively small, which is consistent with the low deposition rate demonstrated in Figure 5 . The grains were sparsely distributed on the substrate, with a tendency of adjoining each other at elevated temperatures. When the temperature increased to $150{ }^{\circ} \mathrm{C}$, the adjacent grains pressed together and formed large numbers of clusters. At $200^{\circ} \mathrm{C}$, the bottoms of the clusters connected with each other and the top of that grew vertically, leading to the network structure formation of granular fluorocarbon films.
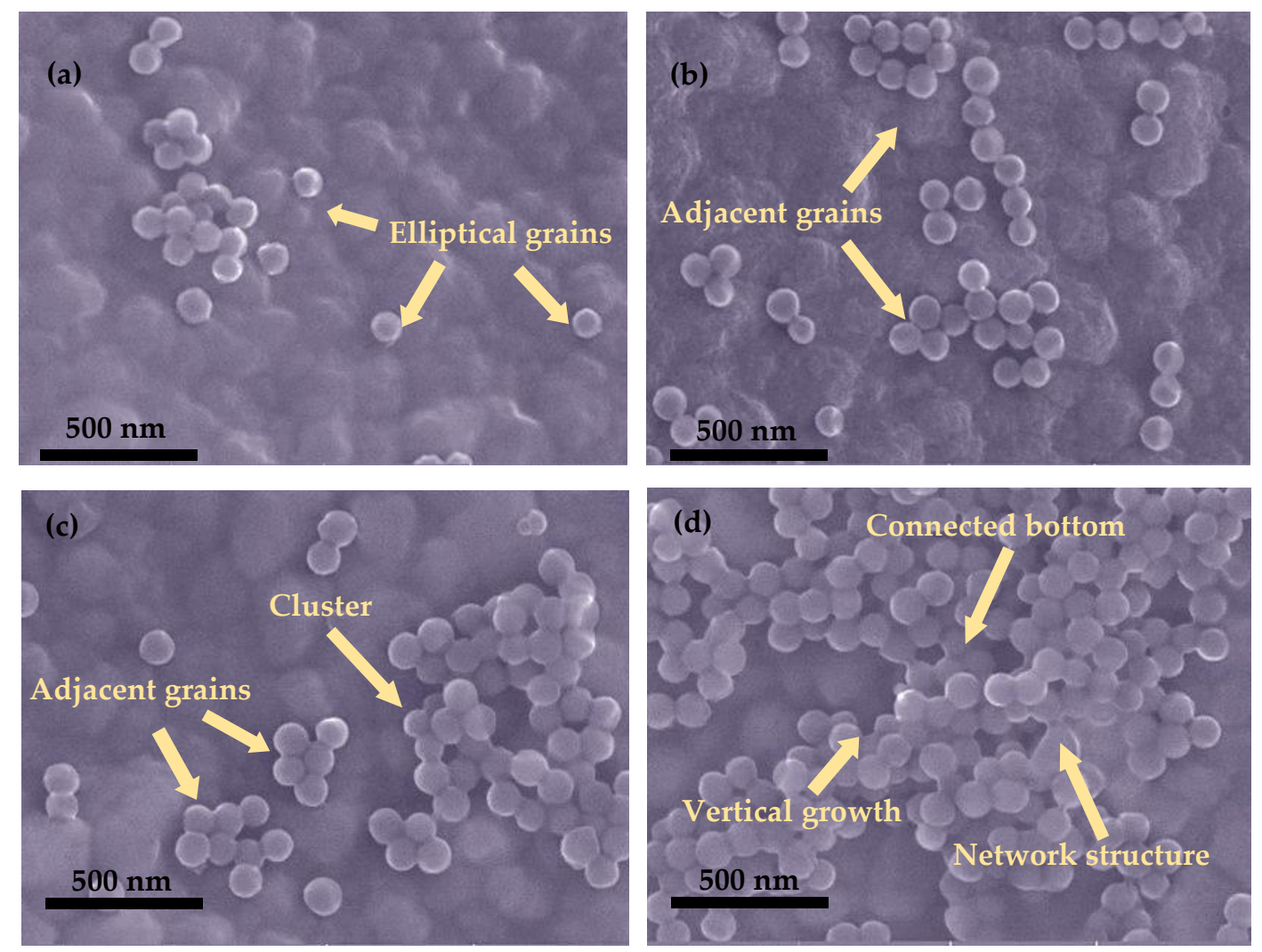

Figure 6. Surface morphology of fluorocarbon films deposited at various sputtering temperatures: (a) $50{ }^{\circ} \mathrm{C},(\mathbf{b}) 100{ }^{\circ} \mathrm{C}$, (c) $150{ }^{\circ} \mathrm{C}$, (d) $200{ }^{\circ} \mathrm{C}$.

Based on the minimum surface area criterion, grains exhibit a spherical shape, with the lowest surface energy. The similar sizes of spherical grains indicate their formation in vapor phase. The surface morphology of granular films is primarily controlled by the mobility and diffusion of ejected fragments on the substrate. Owing to the increased $E^{\prime \prime}{ }_{i}$, the ejected fragments exhibited activated mobility, which contributed to the formation of adjacent grains. The improved diffusion of ejected fragments was achieved by the elevated substrate temperature, which favors grain accumulation and cluster densification [39]. Moreover, as the elevated sputtering temperature is beneficial for higher deposition rates, more grains formed on the substrate. The increased amount of grains reduces the average distance between them and contributes to their combination.

The AFM images in Figure 7 indicate an increased $R_{a}$ from 16.7 to $22.8 \mathrm{~nm}$, via 18.2 and $20.3 \mathrm{~nm}$ with the elevated sputtering temperature. The insert images are corresponding WCAs of fluorocarbon films. Based on the measured contact angles, the $\gamma_{\mathrm{S}}{ }^{\mathrm{OWK}}, \gamma_{\mathrm{S}}{ }^{\mathrm{d}}$ and $\gamma_{\mathrm{S}}{ }^{\mathrm{p}}$ were calculated and are listed in Table 1. As WCA of the reference silicon substrate is $68.2^{\circ}$, the introduction of fluorocarbon films on 
the substrate at $50^{\circ} \mathrm{C}$ dramatically increased the WCA to $107.2^{\circ}$. The further elevated temperature contributed to a higher WCA from $112.1^{\circ}$ to $125.1^{\circ}$, via $122.5^{\circ}$. Based on Equations (1) and (2), the calculated $\gamma_{\mathrm{S}}{ }^{\text {OWK }}$ decreased from 11.82 to $9.52 \mathrm{~mJ} / \mathrm{m}^{2}$. Meanwhile, $\gamma_{\mathrm{S}}{ }^{\mathrm{d}}$ and $\gamma_{\mathrm{S}} \mathrm{p}$ dropped from 15.13 and $1.09 \mathrm{~mJ} / \mathrm{m}^{2}$ down to 9.49 and $0.02 \mathrm{~mJ} / \mathrm{m}^{2}$.
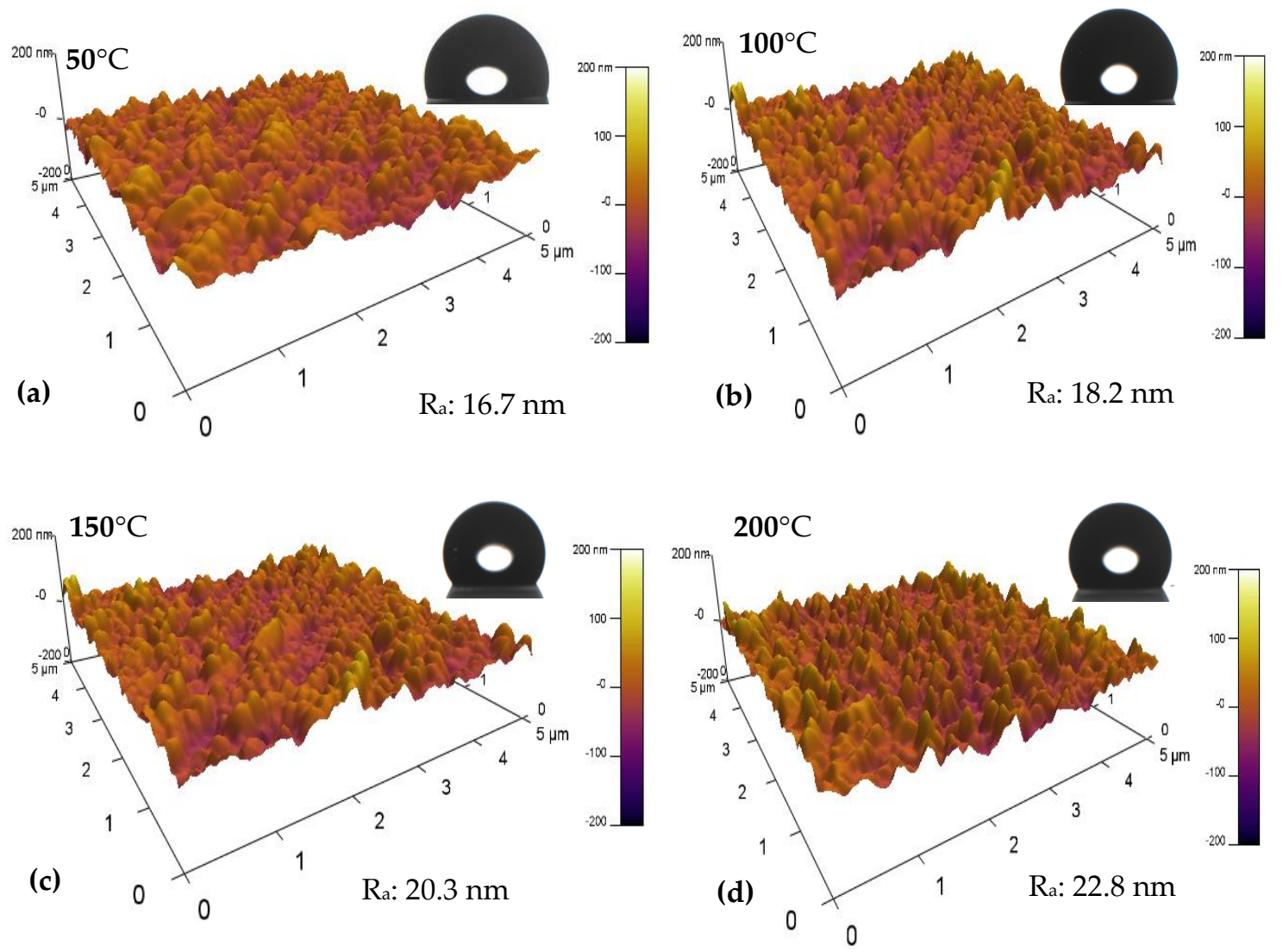

Figure 7. Atomic force microscopy (AFM) images and water contact angles (WCAs) of fluorocarbon films sputtered at $50{ }^{\circ} \mathrm{C}(\mathbf{a}), 100{ }^{\circ} \mathrm{C}(\mathbf{b}), 150{ }^{\circ} \mathrm{C}$ (c) and $200^{\circ} \mathrm{C}$ (d).

Table 1. Surface properties of fluorocarbon films.

\begin{tabular}{cccccc}
\hline Sputtering Temperature $\left({ }^{\circ} \mathbf{C}\right)$ & $\mathbf{R}_{\mathbf{a}}(\mathbf{n m})$ & WCA $\left({ }^{\circ}\right)$ & $\gamma_{\mathbf{s}}{ }^{\text {OWK }}(\mathbf{m N} / \mathbf{m})$ & $\gamma_{\mathbf{s}}{ }^{\mathbf{d}}(\mathbf{m N} / \mathbf{m})$ & $\gamma_{\mathbf{s}}{ }^{\mathbf{p}}(\mathbf{m N} / \mathbf{m})$ \\
\hline 50 & 16.7 & 107.2 & 16.22 & 15.13 & 1.09 \\
100 & 18.2 & 112.1 & 11.82 & 10.74 & 1.08 \\
150 & 20.3 & 122.5 & 10.54 & 10.48 & 0.06 \\
200 & 22.8 & 125.1 & 9.52 & 9.49 & 0.02 \\
\hline
\end{tabular}

The elevated sputtering temperature was confirmed to promote the growth, motion and coalescence of fluorocarbon films according to their nanostructural evolution (Figure 6). For the sputtering temperature of $50{ }^{\circ} \mathrm{C}$, clusters seldom formed on the substrate. Surface roughness mainly depends on the small amount of initially dispersed grains. With the increase of sputtering temperature from 100 to $150{ }^{\circ} \mathrm{C}$, the grains gradually joined with each other, leading to the formation of clusters. As the size of clusters is larger than that of grains, the surface roughness was further enhanced. For sample 4 , prepared at $200{ }^{\circ} \mathrm{C}$, the granular fluorocarbon film showed a nanoscale network structure consisting of larger clusters. The formation of the network structure further enlarged the film's surface roughness. Accordingly, the film surface roughness is determined by three factors (i.e., grain, cluster and network structure), which are dependent on the sputtering temperature.

The surface roughness and chemical composition of fluorocarbon films are considered to have a critical influence on the WCA [40]. According to the Cassie model, the WCA of a rough surface 
is a composite contact angle between water and the compound surface made of fluorocarbon film and air [41]. The elevated temperature from 50 to $200{ }^{\circ} \mathrm{C}$ increased the surface roughness through the deposition of grains and clusters, followed by the formation of the network structure. Compared with grains, clusters are more capable of trapping air. Furthermore, the network structure has the most powerful ability to trap air, thus preventing penetration of the droplet into the film surface. Accordingly, the elevated temperature contributed to enhanced surface roughness, leading to the increased WCA of fluorocarbon films.

Compared with the WCA of the silicon substrate, the increased WCA of fluorocarbon films was mainly attributed to the presence of fluorinated groups, which help to lower $\gamma_{\mathrm{s}}{ }^{\mathrm{OWK}}$ due to their chemical inertness [42]. In addition, XPS results confirmed the increased fluorine-to-carbon (F/C) ratio, resulting in further reduced $\gamma_{\mathrm{s}}$ OWK of fluorocarbon films with elevated temperature (Figure 4). Therefore, both the enhanced surface roughness and the reduced $\gamma_{\mathrm{s}}{ }^{\mathrm{OWK}}$ were responsible for the increased WCA of the films. Table 1 shows that the reduced $\gamma_{\mathrm{s}}{ }^{\mathrm{OWK}}$ was mainly due to the decreased $\gamma_{S}{ }^{d}$ of the fluorocarbon films. Overall, the $\gamma_{s}{ }^{\text {OWK }}$ originates from the unbalanced forces between atoms or molecules inside and interface. The $\gamma_{\mathrm{S}}{ }^{\mathrm{p}}$ is determined by different intermolecular forces (e.g., permanent, induced dipoles and hydrogen bonding), while the $\gamma_{S}{ }^{d}$ known as London forces is caused by instantaneous dipole-induced dipole interactions. Specifically, the $\gamma_{S}{ }^{\mathrm{p}}$ reduced due to fewer unsaturated components (e.g., $\mathrm{C}-\mathrm{C}$ and $\mathrm{C}-\mathrm{CF}$ ) in fluorocarbon films with the elevated temperature [43]. Compared with the slightly changed amount of $\mathrm{C}-\mathrm{F}$, the decreased amount of $\mathrm{C}-\mathrm{CF}$ and increased amount of $C-F_{2}$ contributed to reduce the $\gamma_{S}{ }^{d}$ (Figure 4) $[43,44]$.

Figure 8 reports the Raman spectra $\left(1200-2000 \mathrm{~cm}^{-1}\right.$ ) detecting a G (graphite) peak and a D (disorder) peak. The $\mathrm{G}$ peak was broader and more asymmetric compared to the $\mathrm{D}$ peak. The peak intensities and positions were obtained by deconvolving the spectra. The deconvolved spectra revealed the intensity ratio of $D$ and $G$ peaks $(I(D) / I(G))$, which decreased from 0.74 to 0.46 , via 0.66 and 0.60 . Meanwhile, the corresponding G peak position shifted upward from 1585 to $1609 \mathrm{~cm}^{-1}$, via 1592 and $1606 \mathrm{~cm}^{-1}$, with the elevated temperature from 50 to $200{ }^{\circ} \mathrm{C}$, via 100 and $150{ }^{\circ} \mathrm{C}$.

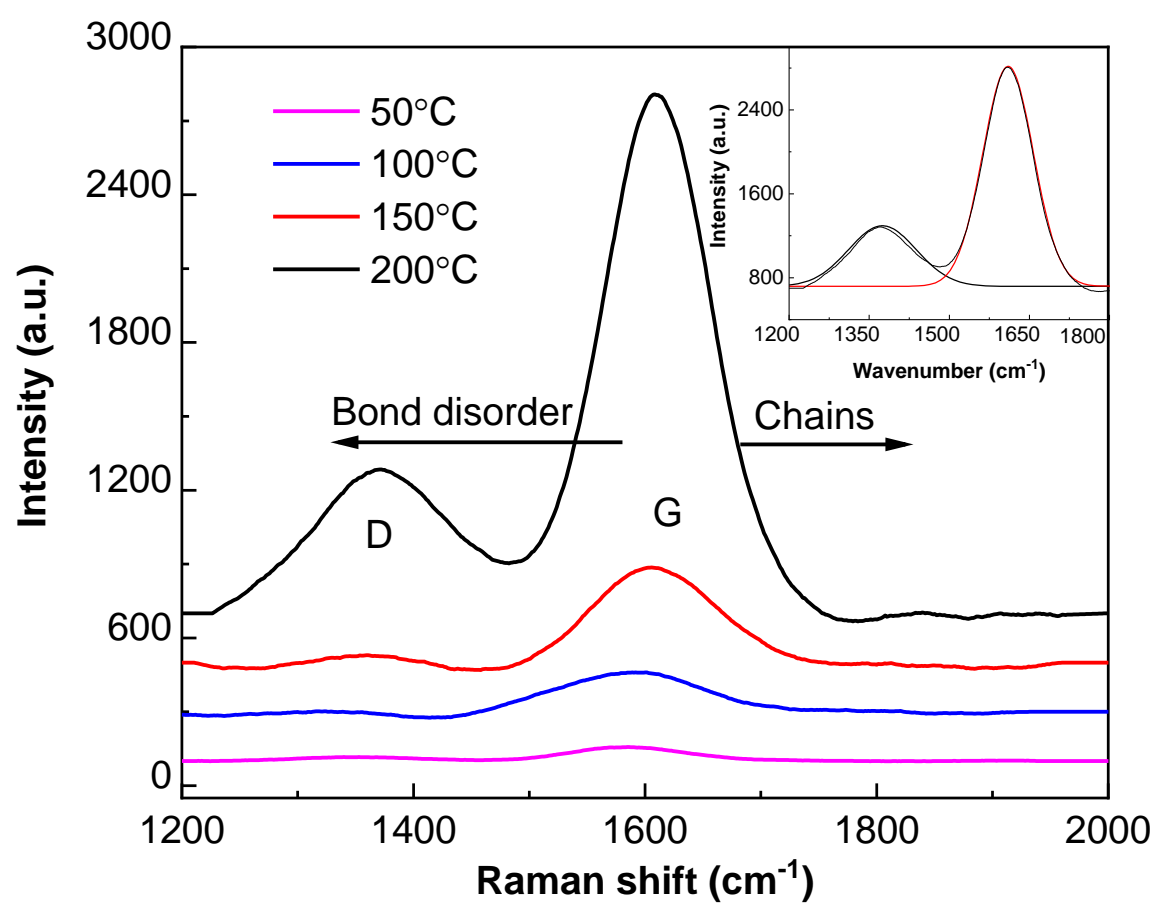

Figure 8. Raman spectra of fluorocarbon films deposited at different sputtering temperatures.

The $G$ peak in Figure 8 was attributed to the symmetric $E_{2 g}$ vibrational mode in graphite-like materials, while the D peak stemmed from the limitation in the graphite domain size induced by 
grain boundaries or imperfections, such as $\mathrm{sp}^{3}$ carbon and other defects [45]. The Raman spectra reflected the amorphous structure of fluorocarbon films with sputtering temperature ranging from 50 to $200{ }^{\circ} \mathrm{C}$. The decreased intensity ratio of $\mathrm{I}(\mathrm{D}) / \mathrm{I}(\mathrm{G})$ and upshifting of the $\mathrm{G}$ peak position towards a higher wavenumber were attributed to the increased proportion of $\mathrm{sp}^{3}$ carbon atoms, accompanying more covalently bonded fluorine to carbon $[46,47]$. From the molecule kinematics viewpoint, the elevated sputtering temperature contributed to prolonging the mean free path of argon atoms and electrons, thus decreasing their collisions. The decreased collisions between argon atoms and electrons reduced the ionization rate of argon ions [48]. As the PTFE target consists of $\mathrm{sp}^{3}$ carbon atoms, the reduced ionization rate, together with the enhanced deposition rate of fluorocarbon films, promoted the formation of a higher proportion of $\mathrm{sp}^{3}$ carbon atoms (Figure 5) [49]. The increased proportion of $\mathrm{sp}^{3}$ carbon atoms is beneficial for the $\mathrm{sp}^{2}$ configuration of olefinic groups with high vibrational frequencies, which leads to the upshifting of the $G$ peak position [46].

\section{Conclusions}

In this work, fluorocarbon film was deposited on silicon substrate at elevated sputtering temperatures from 50 to $200{ }^{\circ} \mathrm{C}$, via 100 and $150{ }^{\circ} \mathrm{C}$. The deposition rate of the films increased from 1.25 to $4.13 \mathrm{~nm} / \mathrm{min}$, and the surface roughness was enhanced from 16.7 to $22.8 \mathrm{~nm}$. Based on the increased WCA of fluorocarbon films from $107.2^{\circ}$ to $125.1^{\circ}$, the calculated $\gamma_{\mathrm{s}}{ }^{\mathrm{OWK}}$ decreased from 16.22 to $9.52 \mathrm{~mJ} / \mathrm{m}^{2}$, accompanied by both the reduction of $\gamma_{\mathrm{S}}{ }^{\mathrm{d}}$ and $\gamma_{\mathrm{S}}{ }^{\mathrm{p}}$. Besides the increased surface roughness, the enhanced $\mathrm{F} / \mathrm{C}$ ratio was also responsible for the WCA increment. The elevated temperature enhanced the $\mathrm{F} / \mathrm{C}$ ratio from 0.99 to 1.24 , due to the increased proportions of saturated components and decreased proportions of unsaturated components. From the molecule kinematics viewpoint, the elevated temperature contributes to prolonging the mean free path of argon ions, argon atoms and ejected fragments, leading to reduced collisions inside the vacuum chamber and the improved sticking coefficient on the substrate. Therefore, elevated temperature contributes to promote fragment deposition on the substrate with increased $\mathrm{F} / \mathrm{C}$ ratio.

Author Contributions: Formal Analysis, F.W.; Investigation, Q.Z.; Resources, K.W. and J.L.; Data Curation, G.X. and W.C.; Writing—Original Draft Preparation, F.W. and Q.Z.; Writing—Review \& Editing, F.W. and Q.Z.

Funding: This research was funded by the National Natural Science Foundation of China [U1537211], National Key Basic Research Program of China (973 Program) [2015CB251003], National Natural Science Foundation of China [51507017] and National "111" Project of the Ministry of Education of China [B08036].

Conflicts of Interest: The authors declare no conflict of interest in the interpretation of data, in the writing of the manuscript and in the decision to publish the results.

\section{References}

1. Kim, M.; Kang, T.W.; Kim, S.H.; Jung, E.H.; Park, H.H.; Seo, J.W.; Lee, S.J. Antireflective, self-cleaning and protective film by continuous sputtering of a plasma polymer on inorganic multilayer for perovskite solar cells application. Sol. Energy Mater. Sol. Cells 2019, 191, 55-61. [CrossRef]

2. Li, W.; Tan, X.D.; Liu, D.P.; Liu, Y.H.; Feng, Z.Q.; Chen, B.X. Growth of Fluorocarbon Films by Low-Pressure Dielectric Barrier Discharge. Plasma Sci. Technol. 2008, 10, 74-77.

3. Xiang, H.; Komvopoulos, K. Effect of fluorocarbon self-assembled monolayer films on sidewall adhesion and friction of surface micro-machines with impacting and sliding contact interfaces. J. Appl. Phys. 2013, 113, 224505. [CrossRef]

4. Vinogradov, I.P.; Lunk, A. Dependence of surface tension and deposition rate of fluorocarbon polymer films on plasma parameters in a dielectric barrier discharge (DBD). Surf. Coat. Technol. 2005, 200, 695-699. [CrossRef]

5. Halindintwali, S.; Knoesen, D.; Swanepoel, R.; Julies, B.; Arendse, C.; Muller, T.; Theron, C.; Gordijn, A.; Bronsveld, P.; Rath, J.K.; et al. Improved stability of intrinsic nanocrystalline Si thin films deposited by hot-wire chemical vapour deposition technique. Thin Solid Films 2007, 515, 8040-8044. [CrossRef] 
6. Huang, H.; Tan, O.K.; Lee, Y.C.; Tse, M.S. Preparation and characterization of nanocrystalline $\mathrm{SnO}_{2}$ thin films by PECVD. J. Cryst. Growth 2006, 288, 70-74. [CrossRef]

7. Kim, S.H.; Kim, M.; Lee, J.H.; Lee, S.J. Self-cleaning transparent heat mirror with plasma polymer fluorocarbon thin film fabricated by continuous roll-to-roll sputtering process. ACS Appl. Mater. Interfaces 2018, 10, 10454-10460. [CrossRef]

8. Gonon, P.; Sylvestre, A. Dielectric properties of fluorocarbon thin films deposited by radio frequency sputtering of polytetrafluoroethylene. J. Appl. Phys. 2002, 92, 4584-4589. [CrossRef]

9. Huang, M.L.; Lu, S.G.; Du, W.Q. Preparation and Characterization of FC Films Coated on PET Substrates by RF Magnetron Sputtering. MATEC Web Conf. 2018, 142, 03008. [CrossRef]

10. Elders, J.; Jansen, H.V.; Elwenspoek, M. Materials analysis of fluorocarbon films for MEMS applications. In Proceedings of the IEEE Micro Electro Mechanical Systems an Investigation of Micro Structures, Sensors, Actuators, Machines and Robotic Systems, Oiso, Japan, 25-28 January 1994; pp. 170-175.

11. Smith, B.K.; Sniegowski, J.J.; Lavigne, G. Thin Teflon-like films for eliminating adhesion in released polysilicon microstructures. Sens. Actuators A Phys. 1998, 70, 159-163. [CrossRef]

12. Iwamori, S.; Hasegawa, N.; Uemura, A. Fluorocarbon polymer thin films prepared by three different types of RF magnetron sputtering systems. Surf. Coat. Technol. 2008, 203, 59-64. [CrossRef]

13. Tang, G.Z.; Ma, X.X.; Sun, M.R. Composition and chemical structure of ultra-thin a-C: F films deposited by RF magnetron sputtering with high pulsed bias. Diam. Relat. Mater. 2007, 16, 1586-1588. [CrossRef]

14. Ma, X.X.; Tang, G.Z.; Sun, M.R. Relationship between mechanical properties and chemical groups in a-C: $F$ films prepared by RF unbalanced magnetron sputter deposition. Surf. Coat. Technol. 2007, 201, 7641-7644. [CrossRef]

15. Roy, R.A.; Messier, R.; Krishnaswamy, S.V. Preparation and properties of r.f.-sputtered polymer-metal thin films. Thin Solid Films 1983, 109, 27-35. [CrossRef]

16. Kim, S.H.; Kim, C.H.; Choi, W.J.; Lee, T.G.; Cho, S.K.; Yang, Y.S.; Lee, J.H.; Lee, S.J. Fluorocarbon Thin Films Fabricated using Carbon Nanotube/Polytetrafluoroethylene Composite Polymer Targets via Mid-Frequency Sputtering. Sci. Rep. 2017, 7, 1451. [CrossRef] [PubMed]

17. Suzuki, Y.; Fu, H.J.; Abe, Y.; Kawamura, M. Effects of substrate temperature on structure and mechanical properties of sputter deposited fluorocarbon thin films. Vacuum 2013, 87, 218-221. [CrossRef]

18. Oya, T.; Kusano, E. Characterization of organic polymer thin films deposited by rf magnetron sputtering. Vacuum 2008, 83, 564-568. [CrossRef]

19. Li, L.; Jones, P.M.; Hsia, Y.T. Characterization of a nanometer-thick sputtered polytetrafluoroethylene film. Appl. Surf. Sci. 2011, 257, 4478-4485. [CrossRef]

20. Liu, Z.J.; Ji, Q.; Zhang, Y.H.; Xia, Y.Z. Deposition of fluorocarbon films by RF magnetron sputtering at varying target-substrate distance. Appl. Mech. Mater. 2011, 50-51, 589-593. [CrossRef]

21. Kylián, O.; Drábik, M.; Polonskyi, O.; Čechvala, J.; Artemenko, A.; Gordeev, I.; Choukourov, A.; Matolínová, I.; Slavínská, D.; Biederman, H. Deposition of nanostructured fluorocarbon plasma polymer films by RF magnetron sputtering of polytetrafluoroethylene. Thin Solid Films 2011, 519, 6426-6431. [CrossRef]

22. Tang, G.Z.; Ma, X.X.; Sun, M.R.; Li, X.D. Mechanical characterization of ultra-thin fluorocarbon films deposited by R.F. magnetron sputtering. Carbon 2005, 43, 345-350. [CrossRef]

23. Biederman, H.; Zeuner, M.; Zalman, J.; Bíková, P.; Slavínská, D.; Stelmasuk, V.; Boldyreva, A. Rf magnetron sputtering of polytetrafluoroethylene under various conditions. Thin Solid Films 2001, 392, 208-213. [CrossRef]

24. Biederman, H. The properties of films prepared by the rf sputtering of PTFE and plasma polymerization of some freons. Vacuum 1981, 31, 285-289. [CrossRef]

25. Lehmann, H.W.; Frick, K.; Widmer, R.; Vossen, J.L.; James, E. Reactive sputtering of PTFE films in argon-CF mixtures. Thin Solid Films 1978, 52, 231-235. [CrossRef]

26. Shao, J.J.; Ren, Z.L.; Yang, Y.L.; Xiao, Y.B.; Yuan, Y. Low Temperature Super-Hydrophobicity of Magnetron Sputtered Polytetrafluoroethylene Coatings. Chin. J. Vac. Sci. Technol. 2017, 2, 154-160.

27. Zhong-Dao, Z.R.; Yu-Tian, H.E.; Ji-Ye, Y.W. Sputtering Apparatus, China. CN patent 104947047A, 30 September 2015.

28. Martinelli, E.; Sarvothaman, M.K.; Alderighi, M.; Galli, G.; Mielczarski, E.; Mielczarski, J.A. PDMS network blends of amphiphilic acrylic copolymers with poly(ethylene glycol)-fluoroalkyl side chains for fouling-release Coatings. I. Chemistry and Stability of the Film Surface. J. Polym. Sci. Part A Polym. Chem. 2012, 50, 2677-2686. [CrossRef] 
29. Zandona, P. The Effects of Changing Deposition Conditions on the Similarity of Sputter-Deposited Fluorocarbon Thin Films to Bulk PTFE. Ph.D. Thesis, University of Delaware, Newark, DE, USA, 2014.

30. Bodas, D.S.; Mandale, A.B.; Gangal, S.A. Deposition of PTFE thin films by RF plasma sputtering on (100) silicon substrates. Appl. Surf. Sci. 2005, 245, 202-207. [CrossRef]

31. Gonon, P.; Sylvestre, A.; Bustarret, E. Investigation of fluorocarbon thin films as dielectric materials for electronic applications. In Proceedings of the 7th International Conference on Properties and Applications of Dielectric Materials, Nagoya, Japan, 1-5 June 2003.

32. Mukherjee, T. Investigation of Post-Plasma Etch Fluorocarbon Residue Characterization, Removal and Plasma-Induced Low-K Damage for Advanced Interconnect Applications. Ph.D. Thesis, University of North Texas, Denton, TX, USA, 2016.

33. Lide, D.R. Handbook of Chemistry and Physics; CRC Press: Boca Raton, FL, USA, 2009.

34. He, J.L.; Li, W.Z.; Wang, L.D.; Wang, J.; Li, H.D. Deposition of PTFE thin films by ion beam sputtering and a study of the ion bombardment effect. Nucl. Instrum. Methods Phys. Res. Sect. B Beam Interact. Mater. At. 1998, 135, 512-516. [CrossRef]

35. Li, L.; Zi, F.T.; Zheng, Y.F. The characterization of fluorocarbon films on NiTi alloy by magnetron sputtering. Appl. Surf. Sci. 2008, 255, 432. [CrossRef]

36. Ngaruiya, J.M. Fundamental Processes in Growth of Reactive DC Magnetron Sputtered Thin Films. Ph.D. Thesis, Rheinisch-Westfälische Technische Hochschule, Aachen, Germany, 2004.

37. Alvarez, R.; Garcia-Martin, J.M.; Lopez-Santos, M.C.; Rico, V.; Ferrer, F.J.; Cotrino, J.; Gonzalez-Elipe, A.R.; Palmero, A. On the Deposition Rates of Magnetron Sputtered Thin Films at Oblique Angles. Plasma Process. Polym. 2014, 11, 571-576. [CrossRef]

38. Houseman, B.L.; Marzocchi, B.E.; Goucher, C.T.M. The Influence of Substrate Temperature on the Sticking Coefficient of Zinc on Glass; Defense Technical Information Center: Fort Belvoir, VA, USA, 1968.

39. Alfonso, E.; Olaya, J.; Cubillos, G. Thin Film Growth through Sputtering Technique and Its Applications. In Crystallization-Science and Technology; IntechOpen: London, UK, 2012.

40. Ji, H.Y.; Chen, G.; Yang, J.; Hu, J.; Song, H.J.; Zhao, Y.T. A simple approach to fabricate stable superhydrophobic glass surfaces. Appl. Surf. Sci. 2013, 266, 105-109. [CrossRef]

41. Cassie, A.B.D.; Baxter, S. Wettability of porous surfaces. Trans. Faraday Soc. 1944, 40, 546-551. [CrossRef]

42. Chambers, R.D. Elimination reactions. In Fluorine in Organic Chemistry; Blackwell Publishing Ltd: Oxford, UK, 2009.

43. Bendavid, A.; Martin, P.J.; Randeniya, L.; Amin, M.S.; Rohanizadeh, R. The properties of fluorine-containing diamond-like carbon films prepared by pulsed DC plasma-activated chemical vapour deposition. Diam. Relat. Mater. 2012, 19, 1466-1471. [CrossRef]

44. Yu, G.Q.; Tay, B.K.; Sun, Z.; Pan, L.K. Properties of fluorinated amorphous diamond like carbon films by PECVD. Appl. Surf. Sci. 2003, 219, 228-237. [CrossRef]

45. Hellgren, N.; Johansson, M.P.; Broitman, E.; Hultman, L.; Sundgren, J.E. Role of nitrogen in the formation of hard and elastic CNx thin films by reactive magnetron sputtering. Phys. Rev. B 1999, 59, 5162. [CrossRef]

46. Ferrari, A.C.; Robertson, J. Interpretation of Raman spectra of disordered and amorphous carbon. Phys. Rev. B. 2000, 61, 14095. [CrossRef]

47. Mazánek, V.; Jankovský, O.; Luxa, J.; Sedmidubský, D.; Janoušek, Z.; Šembera, F.; Mikulics, M.; Sofer, Z. Tuning of fluorine content in graphene: Towards large-scale production of stoichiometric fluorographene. Nanoscale 2015, 7, 13646-13655. [CrossRef]

48. Güttler, D. An Investigation of Target Poisoning during Reactive Magnetron Sputtering; Wissenschaftlich-technische Berichte; Forschungszentrum Dresden-Rossendorf: Marienberg, Deutschland, 2009.

49. Zi, F.T. The Preparation and Properties Research of Fluorinated Amorphous Carbon Films on NiTi Alloy. Master's Thesis, Harbin Engineer University, Harbin, China, 2008.

(C) 2019 by the authors. Licensee MDPI, Basel, Switzerland. This article is an open access article distributed under the terms and conditions of the Creative Commons Attribution (CC BY) license (http://creativecommons.org/licenses/by/4.0/). 